\title{
A Comparative Analysis of Processes of Conceptual Change for the Enhancement of Implementation of Green Energy Education and Training
}

\author{
Andreas Ahrens, Jel̦ena Zaščerinska, Christoph Lange, and Ludmila Aḷeksejeva
}

\begin{abstract}
Green energy is promoted via education and training. In education, concepts are the cornerstone in knowledge creation. Comparative analysis in the present paper assists in the discovery of patterns of processes of conceptual change. The aim of this paper is to compare processes of conceptual change underpinning the enhancement of implementation of green energy education and training. Our motivation here is to identify an efficient process of conceptual change for the enhancement of implementation of green energy education and training. The novelty of the research presented in this paper lies in the formulated implications for research and practice devoted to the efficient implementation of green energy education and training.
\end{abstract}

Index Terms-Component, green energy education and training, processes of conceptual change, comparative analysis.

\section{INTRODUCTION}

In the light of climate change, the energy sector shifts to green energy and renewable sources. Renewables are expected to supply four-fifths of the world's electricity by 2050, massively cutting carbon emissions and helping to mitigate climate change. In order to succeed at a macro-level societal shift, green energy education and training is widely recognized as the efficient way of stipulating the transition from fossil fuels' energy to renewable sources.

The relationship between green energy as well as education and training is of two-fold nature as shown in Fig. 1:

- on the one side, green energy is promoted via education and training,

- on the other hand, education and training is the driver of green energy.

In education and training, concepts are found to be at the heart of knowledge creation [1]. Fig. 2 demonstrates the inter-connections between green energy, education and training as well as concepts.

Further on, concepts are bi-modal phenomena in education. It should be noted that by bi-modal phenomenon, a phenomenon that obtains or exhibits two contrasting modes

Manuscript received June 5, 2020; revised November 12, 2020.

Andreas Ahrens is with Hochschule Wismar, University of Technology, Business and Design, Philipp-Müller-Straße 14, 23966 Wismar, Germany (e-mail: andreas.ahrens@hs-wismar.de).

Jelena Zaščerinska and Ludmila Aleksejeva are with Department of Higher Education Research at Centre for Education and Innovation Research / CEIR, Riga, Latvia (e-mail: Ceir2012@gmail.com, asava@inbox.lv).

Christoph Lange is with Hochschule für Technik und Wirtschaft Berlin, University of Applied Sciences, Wilhelminenhofstraße 75A, 12459 Berlin, Germany (e-mail: Christoph.lange@HTW-Berlin.de). or forms is meant [2]. On the one hand, concepts present forms or levels of knowledge in education [1] and content [3]. On the other hand, a concept is defined as a verbal abstraction drawn from observation of a number of specific cases [4]. Additionally, concepts are not static, they are dynamic, they change in time and develop in content.

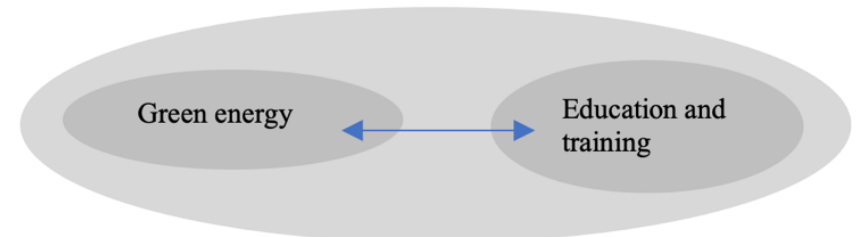

Fig. 1. The relationship between green energy as well as education and training.

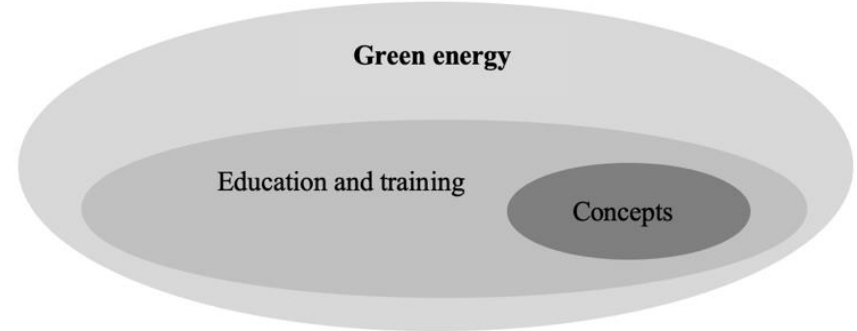

Fig. 2. The relationship between green energy, education and training as well as concepts.

Against this background, a little attention was paid to processes of conceptual change in green energy in general and education and training in particular. The research questions are:

1) How to implement the process of conceptual change in green energy education and training?

2) What are the phases/stages of the process of conceptual change?

3) What is the sequence of the phases/stages of the process of conceptual change?

The aim of this paper is to compare processes of conceptual change underpinning the enhancement of implementation of green energy education and training. Our motivation here is to identify an efficient process of conceptual change for the enhancement of implementation of green energy education and training. The novelty of the research presented in this paper lies in the formulated implications for research and practice devoted to the efficient implementation of green energy education and training. Comparative analysis in the present paper assists in the discovery of patterns [5] of processes of conceptual change. The present comparative analysis is carried out within a comparative study. 
The remaining part of the paper is organised as following: Section II introduces the design of the comparative study. Section III presents a couple processes of conceptual change found in scientific literature. Section VI demonstrates findings of the comparative analysis. Section V delivers implications for research and practice devoted to the efficient implementation of green energy education and training. Finally, some concluding remarks are provided followed by a short outlook on interesting topics for further work.

\section{Design OF THE COMPARATIVE StUdy}

The present part of the paper demonstrates the design of the empirical study.

Comparative study as a qualitative research design has been employed [6]. The exploratory type of the comparative study has been applied [7]. The exploratory type of the comparative study aims to generate new hypotheses and questions [7]. The exploratory methodology proceeds as follows [7]:

1) 'conceptualization' in Phase 1 ,

2) detailed description of phenomena to be investigated, with full attention paid to the contexts in terms of its historical, geographical, cultural, political, religious, and linguistic (etc.) features in Phase 2,

3) the data collection in Phase 3,
4) explanation through the development of hypotheses and/or research questions in Phase 4,

5) re-consideration of the initial questions and application of the findings to other situations in Phase 5.

The exploratory methodology of the empirical study proceeds [8]

1) from exploration in Phase 1

2) through analysis in Phase 2

3) to hypothesis/research question development in Phase 3.

The data were collected in the scientific literature devoted to conceptual change available on the Internet in October 2019. The data description was based on the term definition to be considered as the statement of the phenomenon notion, elements and process [9]. The collected data were processed via structuring and summarizing content analysis [10]. The collected data is interpreted by the researcher(s) of the present investigation as the interpretive paradigm proposes [11].

\section{Processes of CONCEPTUAL Change}

The present part describes processes of conceptual change collected in scientific literature.

Table I shows a couple of discovered patterns of concept notions and concept structures in relation to the data description method used in the present research.

TABLE I: CONCEPT NOTIONS AND STRUCTURES IN SCIENTIFIC LITERATURE

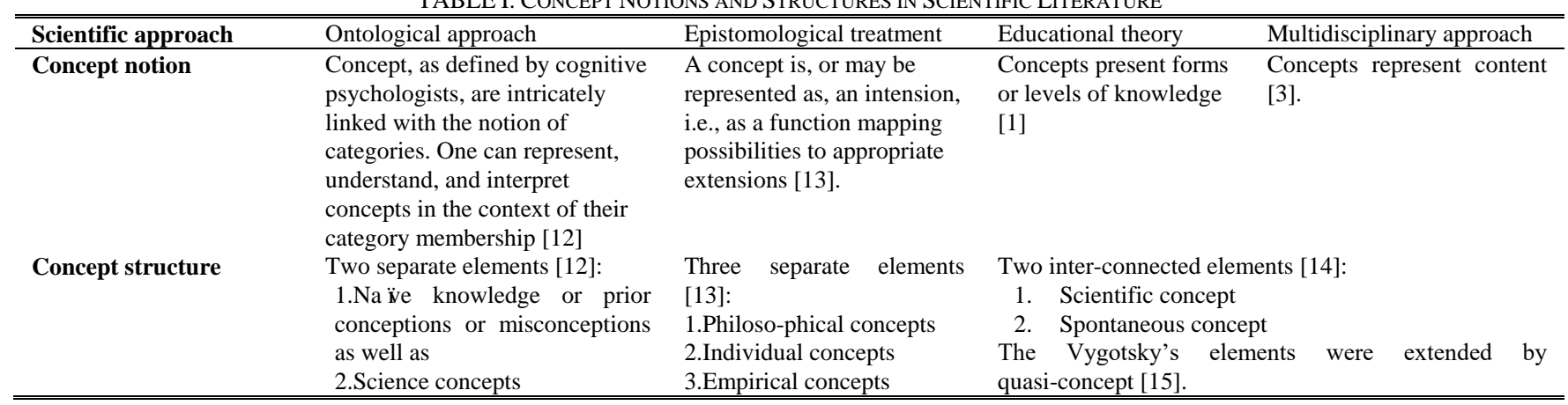

TABLE II: SCHEME FOR CONCEPTUAL CHANGE BY STEPHANS [16]

\section{Step}

1.Commit to outcome

2.Expose beliefs

3.Confront Beliefs

4.Accommo-date concept

5.Extent the concept

6.Go beyond

Purpose

Purpose: to help students become aware of their own beliefs

Purpose: to help students talk about their beliefs in small and large groups

Purpose: to provide experience in which students can test their beliefs through activity, talk and writing

the

Purpose: to help students resolve conflicts between his or her ideas and beliefs and what has been observed or presented

Purpose: to provide situations including personal and daily life in which students can extend concepts or ideas to new situations

Purpose: to encourage students to continue thinking about the concept by pursuing additional questions or problems of interest

\section{Activity}

Educator presents a situation either by posing a question, presenting a challenge or asking students to make a prediction. Students are asked to commit to an outcome

Based on the initial step, teacher can ask students to share their idea verbally with a partner, a small group or the whole class or describe an idea in writing (data sheet or learning $\log$ )

Students have an opportunity to confront their beliefs by engaging in a hands on activity in small groups, debating ideas, conduct inter-views, or reading

In this phase educator asks questions based on the activity to help students explain their observations and to make sense of their data

Educator helps students to apply their ideas to other situations including daily life

The key to this last phase is to extend students' thinking about the topic. Asking students to pose additional questions, to bring in examples of phenomena related to the topic are ways to go beyond
A couple of scientific works addresses the issue of process of conceptual change. Process of conceptual change is defined by Chi and Roscoe [12] as the shift of concepts across ontological categories and/or boundaries. Spohn [13] proposes various stages of a concept (It means that philosophical, individual and empirical concepts can have 
various stages of their change). What is important Spohn [13] emphasizes that concepts have to be shared by the community (shared concepts). The scheme for conceptual change by Stepans [16] as highlighted in Table II promotes learning for all students and helps educators to recognize and to incorporate students' prior knowledge into their teaching. Stepans suggests the following stages for conceptual change [16]:

1) Help students to become dissatisfied with their existing conception,

2) Help students to achieve a minimal initial understanding of the scientific conception,

3) Make the scientific conception plausible to students,

4) Show the scientific conception as fruitful or useful in understanding a variety of situations.

However, the scheme for conceptual change by Stepans [16] as shown in Table II provides the implication of science knowledge on the social plane forgetting about vital necessity of development of the system of external and internal perspectives [17]. In turn, concept formation by Vygotsky includes the unity of scientific (academic) and spontaneous (everyday) concepts and proceeds from scientific (academic) to spontaneous (everyday) concept [14], [15], [18]. Vygotsky's concept formation was further enhanced by Zaščerinska [17] with quasi-concept proposed by Robbins [15] and resulted first in three phases of the process of conceptual change.

\section{FINDINGS OF THE COMPARATIVE ANALYSIS}

Comparative analysis allows describing patterns of the process of conceptual change to be such as

- a system process as its properties are linked,

- a complex process as its elements are intertwined,

- a linear process as it proceeds from one stage/phase to another,

- a cyclic process as it can be repeated,

- of social nature as it changes within and by society and/or community ("shared concepts" by Spohn [13],

- of bi-module nature as it includes both external (scientific/academic concepts) and internal (spontaneous concepts) perspectives [17].

Later, the three-phase process of conceptual change was modernized to the five-phase process of conceptual change [17] as illustrated in Fig. 3.

\section{IMPLICATIONS FOR RESEARCH AND PRACTICE}

Such implications for research on the processes of conceptual change are identified as the process of conceptual change has become a many-fold phenomenon, is becoming a complex (linked and intertwined elements) phenomenon, being a complex phenomenon requires the application of innovative paradigms and approaches for theoretical analysis, investigation could be based on novel principles of analysis such as the system of external and internal perspectives.

Implications for practice of green energy education and training include such recommendations as

1) While implementing green energy education and training teachers have to follow the three phases of the process of conceptual change:

- from scientific concept

- through quasi-concept

- to spontaneous concept.

2) The phase of scientific concept is relevant to teaching, quasi-concept - to peer-learning, and spontaneous concept - to learning.

3) All the three phases of the process of conceptual change are important. That means that, despite the growing popularity of peer-learning that prevails in modern organization of the educational process, all the three phases should be included in the process of conceptual change (from scientific concept through quasi-concept to spontaneous concept).

4) The education and training process should follow the indicated sequence of phases of the process of conceptual change: from scientific concept through quasi-concept to spontaneous concept.

5) Moreover, the recommendation here is the role of teachers as mentors for students' self-discovery and self-realization; to motivate students, to stimulate their interests, to help them to develop their own structure and style, as well as to help them to evaluate their performance and be able to apply these findings [19].

6) In order to provide each student with the opportunity to construct his/her own concept of green energy, the use of communication games, information-gap activities, role plays, simulations, dialogues, prepared talks and discussions has been recognized efficient for the process of conceptual change in the green energy education and training [16].

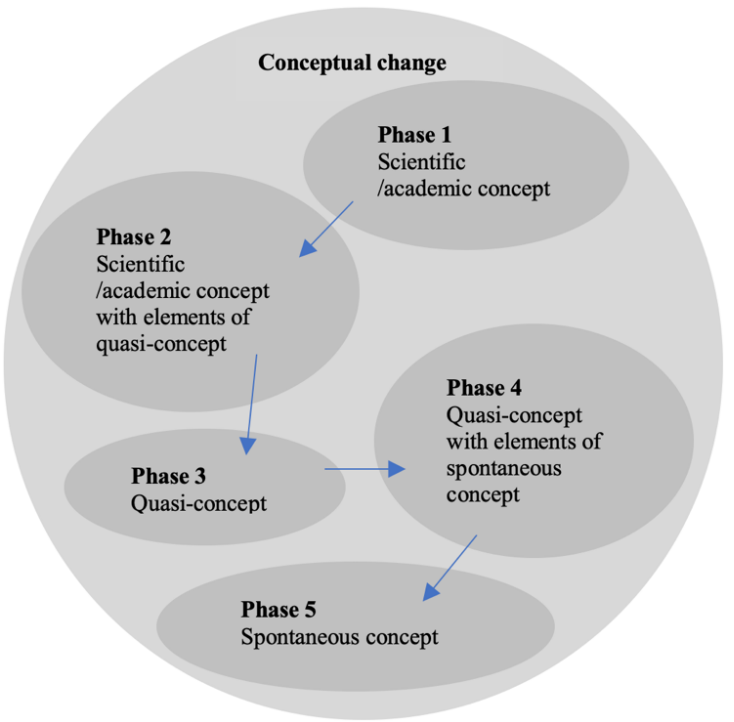

Fig. 3. Five phases of the process of conceptual change [17].

\section{CONCLUSIONS}

The comparative analysis carried out within the comparative study allows identifying such patterns in the process of conceptual change as

- a system process,

- a complex process,

- a linear process, 
- a cyclic process,

- of social nature,

- of bi-module nature.

These patterns in the process of conceptual change provide the substantial basis for the enhancement of the implementation of green energy education and training

- from the contemporary mostly peer-based process of conceptual change as well as education and training,

- to the three phases of the process of conceptual change:

a) from teaching scientific concepts

b) through peer-learning of quasi-concepts

c) to learning of spontaneous concepts.

The newly formulated research questions has been put forward: Is the process of conceptual change implemented in three phases (from teaching scientific concepts through peer-learning of quasi-concepts to learning of spontaneous concepts) in green energy education and training efficient?

The present work has some limitation. The inter-connections between notion, elements and process as a definition have been set. The limitation is the analysis of scientific literature devoted to conceptual change available on the Internet. Another limitation is the analysis of scientific literature devoted to conceptual change available on the Internet only in the selected languages, namely English, Russian and Latvian.

Further work will focus on the validation of the model of the enhanced implementation of green energy education and training in the three phases: from teaching through peer-learning to learning. Implementation of green energy education and training in the three phases (from teaching through peer-learning to learning) in different cultural environments will be compared, too. Search for innovative paradigms, approaches and principles to construct the process of conceptual change will be carried out. Discovery of patterns of the process of conceptual change as well as green energy education and training will be continued.

\section{CONFLICT OF INTEREST}

The authors declare no conflict of interest.

\section{AUTHOR CONTRIBUTIONS}

Jeḷena Zaščerinska, Andreas Ahrens and Christoph Lange conceived of the presented idea. Jel̦ena Zaščerinska designed the model, tables and figures. Christoph Lange, Andreas Ahrens and Ludmila Aḷeksejeva verified the analytical methods. All authors discussed the research results and findings as well as commented on the manuscript. All authors had approved the final version.

\section{REFERENCES}

[1] I. Žogla, "Problems of modern educational theories," 2001.

[2] A. Ahrens and J. Zaščerinska, "Students' attitude to interdisciplinary research," in Proc. the International Scientifical Conference on Society, Integration, Education, vol. I, 2014, pp. 13-23.

[3] H. Niemi, "Why from teaching to learning?" Programme of the European Conference on Educational Research in Gothenburg, Sweden, 2008, pp. 12-13.

[4] J. H. Watt and S. Berg, Research Methods for Communication Science, Pearson, 1995.

[5] C. Pickvance, "Four varieties of comparative analysis," Journal of Housing and the Built Environment, 2001, vol. 16, no. 7.
[6] U. Flick, "Design and process in qualitative research," in U. Flick, E. Von Kardoff \& I. Steine (Eds), A Companion to Qualitative Research, pp. 146-152, Glasgow: SAGE, 2004.

[7] D. Phillips, "Comparative education: Method," Research in Comparative and International Education, vol. 1, no. 4, 2006, pp. 304-319.

[8] A. Ahrens, O. Bassus, and J. Zaščerinska, "Bi-professional curriculum in higher education: Context analysis," in Proc. 6th ICEBE International Conference on Engineeirng and Business Education Innovation, Entrepreneurship and Sustainability, Windhoek, Namibia, 2013, pp. 101-107.

[9] A. Ahrens, J. Zaščerinska, and N. Andreeva, "Engineering students' blended learning in higher education," in Proc. International Scientifical Conference Society, Integration, Education, 2013.

[10] U. Flick, A Companion to Qualitative Research, Glasgow: SAGE, 2004.

[11] N. Gruenwald, A. Ahrens. J. Zaščerinska, and J. Melnikova, "Digital entrepreneurship as a means of integration of immigrants and asylum seekers into labour market in baltic countries," in Proc. 5th International Scientific Conference on "Modern Economics", 2018, pp. 161-170.

[12] M. T. H. Chi and R. D. Roscoe, "The processes and challenges of conceptual change," in Limón M., Mason L. (eds) Reconsidering Conceptual Change: Issues in Theory and Practice, Springer, Dordrecht, 2002.

[13] W. Spohn, "Changing concepts," in W. Spohn, Causation, Coherence, and Concepts, Springer, Dordrecht, 2008, pp. 329-334.

[14] L. Vygotsky, "The development of scientific concepts in childhood," Cambridge, MS: MIT, p. 287.

[15] D. Robbins, "Vygotsky's and Leontiev's non-classical psychology related to second language acquisition," in D. Cunningham, D. Markus, J. Valdmanis ... [u.c.] (Eds), International Nordic-Baltic Region Conference of FIPLV Innovations in Language Teaching and Learning in the Multicultural Context, 2007, pp. 47-57.

[16] J. Stepans, The Conceptual Change Model, Saiwood Publications, 2005.

[17] J. Zaščerinska, Development of Students' Communicative Competence within English for Academic Purposes Studies, Verlag: Mensch \& Buch., 2013, ISBN-13: 978-3-86387-359-2.

[18] L Ligotskis, “Domāšana un runa. Izdevniecība,” EVE” Rīga, 2002.

[19] E. Maslo, "Transformative learning space for life-long foreign languages learning," International Nordic-Baltic Region Conference of FIPLV Innovations in Language Teaching and Learning in the Multicultural Context, 2007, pp. 38-46.

Copyright (C) 2021 by the authors. This is an open access article distributed under the Creative Commons Attribution License which permits unrestricted use, distribution, and reproduction in any medium, provided the original work is properly cited ( $\underline{\text { CC BY 4.0) }}$.

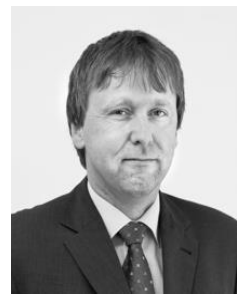

Andreas Ahrens received the Dr.-Ing. and Dr.-Ing. habil. degree from the University of Rostock in 2000 and 2003, respectively. In 2008, he became a professor for signal and system theory at Hochschule Wismar, University of Technology, Business and Design, Germany. His main field of interest includes error correcting codes, multiple-input multiple-output systems, iterative detection for both wireline and wireless communication as well as social computing.

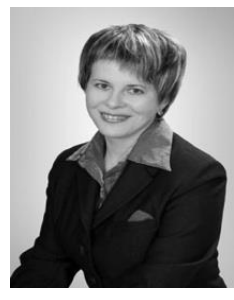

Jelena Zaščerinska was awarded the Dr. Degree by University of Latvia in 2011. In 2012 she became a leading researcher at Centre for Education and Innovation Research, Latvia. In 2012 she was bestowed expert rights by Latvian Council of Science, in 2013 - by Horizon 2020, in 2017 - by National Science Centre, Krakow, Poland. Since 2013 she has been actively acting as Editorial Board Member and Reviewer in international scientific journals. 
Christoph Lange received the Dipl.-Ing. degree (diploma) in electrical engineering and the Dr.-Ing. degree (doctorate) in communications engineering from the University of Rostock, Germany, in 1998 and 2003, respectively. From 2006 to 2018 he worked for different research and innovation departments at Deutsche Telekom in Berlin. Currently he is a professor of communication networks and systems at Hochschule für Technik und Wirtschaft Berlin, University of Applied Sciences. His research interests include several aspects of communications engineering as well as design and energy efficiency of communication networks.

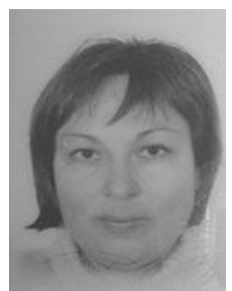

Ludmila Aleksejeva got the master degree in education management from Riga Teacher Training and Educational Management Academy, Riga, Latvia, in 2006. In 2012 she joined Centre for Education and Innovation Research, Latvia. She is actively involved in implementation of international educational projects. 